\title{
Preface to A Close Look at Catalysis at Surfaces: A Special Issue in Honor of Prof. Norbert Kruse on the Occasion of his 70th Birthday
}

\author{
Thierry Visart de Bocarmé ${ }^{~}$. Cédric Barroo ${ }^{1}$
}

Accepted: 2 November 2020 / Published online: 16 November 2020

(c) Springer Science+Business Media, LLC, part of Springer Nature 2020

This special issue of "Topics in Catalysis" has been set up to celebrate a scientist, a mentor, and a friend Professor Norbert Kruse on the occasion of his 70th birthday (Fig. 1).

Norbert Kruse was conferred a doctoral degree from the Technical University of Berlin after research studies at the Fritz-Haber-Institut der Max Planck Gesellschaft in Berlin. He previously received a diploma in chemistry and chemical engineering from the same university. Norbert pursued his passion for research at the ETH Zurich where he later became a lecturer. In 1994, he moved to Belgium to the Université libre de Bruxelles where he was appointed full professor and became an internationally recognized researcher and group leader in the area of surface science and heterogeneous catalysis. Since 2013, Norbert holds a joint appointment at Washington State University as Voiland Distinguished Professor in the Gene and Linda Voiland School of Chemical Engineering and Bioengineering, and at Pacific Northwest National Laboratory. Norbert is currently leading a research group with a strong focus on applied heterogeneous catalysis with the development of sustainable catalytic processes by using renewable feedstocks.

It is fair to say that to reach this ultimate goal, Norbert took the challenge from different and complementary perspectives. During his doctoral studies, Norbert has been mentored by professor Jochen H. Block, a pioneering inventor in the application of field emission methods to the investigation of surface processes at the atomic scale. With the emergence of commercially available scanning probe microscopies in the late eighties, field emission/ion microscopies gradually became less popular. Many would have forecasted a complete loss of that heritage. However, this

Thierry Visart de Bocarmé

Thierry.Visart.de.Bocarme@ulb.be

Cédric Barroo

Cedric.Barroo@ulb.ac.be

1 Université Libre de Bruxelles, Avenue Franklin Roosevelt 50, CP243, 1050 Brussels, Belgium

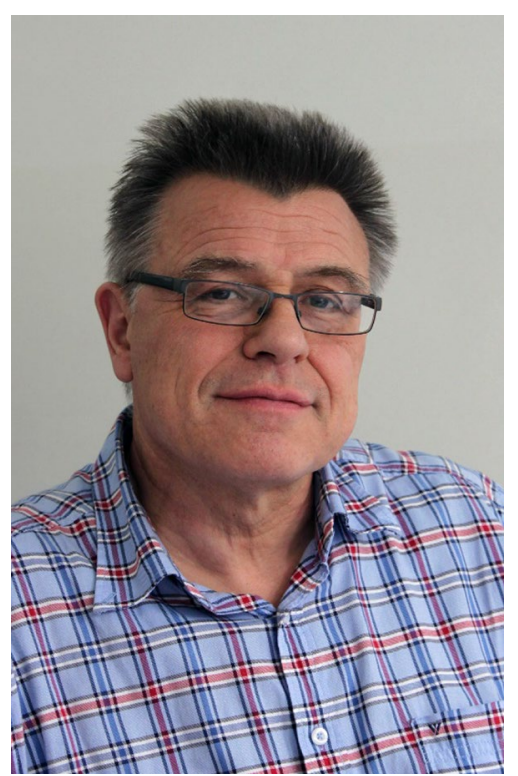

Fig. 1 Prof. Norbert Kruse

was not to discourage Norbert who never in his career fell in the easiness of mainstream research themes. Accordingly, he became one of the very few on this planet to master those methods, and more importantly, to teach them to the next generations to which we, guest editors, belong. This perseverance certainly led Norbert to be elected president of the International Field emission Society from 2008 to 2014. For some years, field emission methods become exponentially popular through the atom-probe tomography, one of the very few methods able to bridge the nanoworld with the materials science. More recently, an increased attention is being paid to the influence of the local electric field on reactions and surface reactions. This is not a recent discovery to Norbert who highlights, since many years, the existence of experimental techniques able to show those effects. 
The bottom-up approach as fascinating as it may be, remains incomplete without embracing complex catalytic processes. During his Belgian years, Norbert developed a top-down viewpoint to get insight into the detailed mechanisms of Fischer-Tropsch catalysis and related reactions using transient kinetic methods on "real" catalysts. This approach shows the advantage to deliver quantitative information that can be integrated at an upper scale and provided illuminating results with regard to a modified Fischer Tropsch synthesis in which oxygenates rather than diesel fuel can be made the dominating products. In this context, Norbert was also the inventor of a new catalyst preparation route using concepts that are similar to those nowadays applied in research with metal organic frameworks. This opened a way to tailor catalytic materials with high selectivities for oxygenates under conditions that perfectly fit with the principles of a greener chemistry.

Norbert has published over 220 peer-reviewed papers and holds several patents. In the early 2000's, he was a guest professor in the group of professor Robert Schlögl at the Fritz-Haber Institute in Berlin and in the group of Professor Gabor Somorjai at the University of California at Berkeley. He served as Editor-in-Chief of two journals, Catalysis Letters and Topics in Catalysis. He is an inaugural fellow of the International Field Emission Society. He has been a member of the supervisory board of BOSAL Company, a leading manufacturer of exhaust systems and catalytic converters, and has served between 1997 and 2015 as executive chairman of the CAPoC conferences (Congress on Catalysis and Automotive Pollution Control), a successful series which will have its twelfth edition in 2022, with Norbert being an honorary chairman.

As friends, former students, and colleagues, we guest editors, would like to emphasize some of Norbert's numerous human qualities. We certainly keep excellent recollections of long discussions when a draft paper was on the table. Challenges, imagination, creativity, open-mindedness, scientific rigor are some of the words that arise when we evoke Norbert's involvement in a research study, from its idea to its publication. We don't forget the word freedom however. Norbert isn't the first to impose every morning a rigid research frame for the rest of the day. Whereas goals are accurate, the travel to reach them are very often left to the liberty of his researchers, leaving them the liberty to make excursions outside a central research track. This approach turned out to be very fruitful and produced many unexpected discoveries of the highest interest. Nanosized target patterns and field-induced oscillations are examples to name some but a few of his surface science work. In more recent times his demonstration for the occurrence of a $\mathrm{CO}$ insertion leading to chain lengthening in the Fischer-Tropsch reaction to functionalized hydrocarbons provided unprecedented insight into the mechanism of this reaction.

To conclude, we weren't surprised to see so many positive responses to our invitations to set-up this special issue. Although the pandemic had shuffled the priorities and commitments in all the research groups, we are proud to deliver today this collection of original research articles to celebrate Norbert's 70th birthday.

The journey continues.

Publisher's Note Springer Nature remains neutral with regard to jurisdictional claims in published maps and institutional affiliations. 